\title{
Biological activities of recombinant Manchurian trout FSH and LH: their receptor specificity, steroidogenic and vitellogenic potencies
}

\author{
Hyeyeon Ko, WooDong Park, Dae-Jung Kim¹, Makito Kobayashi ${ }^{2}$ and Young Chang Sohn \\ Division of Marine Molecular Biotechnology, Faculty of Marine Bioscience and Technology, Kangnung National University, Gangneung 210-702, South Korea \\ ${ }^{1}$ Aquaculture Research Team, Headquarters for Bioscience and Technology, National Fisheries Research and Development Institute, Busan 619-902, South Korea \\ ${ }^{2}$ Department of Biology, Division of Natural Sciences, International Christian University, Tokyo 181-8585, Japan \\ (Requests for offprints should be addressed to Y C Sohn; Email: ycsohn@ kangnung.ac.kr)
}

\begin{abstract}
Gonadotropins (GTHs), FSH and LH, play central roles in vertebrate reproduction. Here, we report the production of biologically-active recombinant FSH (r-mtFSH) and LH (r-mtLH) of an endangered salmon species, Manchurian trout (Brachymystax lenok), by baculovirus in silkworm (Bombyx morl) larvae. The biological activities of the recombinant hormones were analyzed using COS-7 cell line transiently expressing either amago salmon FSH or LH receptor. The steroidogenic potency of the r-mtFSH and r-mtLH was examined by a culture system using rainbow trout follicles in vitro. In vivo, bioactivity was assessed by measuring ovarian weight, oocyte diameter, and plasma steroid hormone levels in female rainbow trout. Moreover, inducing potency of milt production were examined in vivo using goldfish. Our results demonstrated that the r-mtFSH and r-mtLH were successfully produced in the baculovirus-silkworm system and recognized by their cognate receptors specifically in vitro. The production of estradiol-17 $\beta(E 2)$ and testosterone $(T)$ was stimulated by the r-mtFSH and r-mtLH respectively, from the full-grown follicles of rainbow trout, whereas both E2 and T were increased by relatively higher doses of the recombinant hormones from the follicles of the maturing stage. In in vivo assay, injection of the r-mtFSH but not r-mtLH increased ovarian weight, oocyte diameter, and plasma E2 levels in immature rainbow trout. Injection of both r-mtFSH and r-mtLH induced milt production in male goldfish. In conclusion, the present study strongly suggests that the r-mtFSH and r-mtLH have distinct biological properties, such as a specific responsiveness for the cognate receptor, steroidogenic, and vitellogenic activities for ovarian follicles in salmonids. These recombinant FSH and LH may be applied for future studies on the gonadal development and maturation in fishes as well as the endangered salmon species.
\end{abstract}

Journal of Molecular Endocrinology (2007) 38, 99-111

\section{Introduction}

The gonadotropins (GTHs), follicle-stimulating hormone (FSH) and luteinizing hormone (LH), are produced in the pituitary gland of all vertebrates including fish species and they are the key regulators of gonadal development and reproduction. Together, with thyrotropin (TSH) and chorionic gonadotropin (CG), GTHs are members of the glycoprotein hormone family and each member is a heterodimer consisting of two subunits termed $\alpha$ and $\beta$ (Pierce \& Parsons 1981, Suzuki et al. 1988a, Swanson et al. 2003). These heterodimeric glycoproteins are reported to carry highly conserved glycosylation sites, and the attached oligosaccharides are related to the hormone's biosynthesis, half-life, and biological activity both in fishes as well as in mammals (Ulloa-Aguirre et al. 1999, Zenkevics et al. 2000, Klein et al. 2003). These hormones react to specific receptors at the reproductive organs which is an essential requirement for their physiological action
(Simoni et al. 1997, Dufau 1998, Kumar \& Trant 2001, Bogerd et al. 2005).

In fishes, FSH is considered to regulate early phases of gametogenesis, such as vitellogenesis and spermatogenesis, whereas LH is responsible for the final maturation processes, such as oocyte maturation, ovulation, spermiation, and milt production (Yaron et al. 2003, Kobayashi et al. 2006). Despite differences in detailed steroidogenic potency, both FSH and LH stimulated in vitro production of estradiol-17 $\beta$ (E2) by vitellogenic ovarian tissues in chum salmon, Oncorhynchus keta (Suzuki et al. 1988b), coho salmon, O. kisutch (Planas et al. 2000), goldfish, Carassius auratus (Van Der Kraak et al. 1992), red seabream, Pagrus major (Tanaka et al. 1993), and tuna, Thunnus obesus (Okada et al. 1994), and in vitro 11-ketotestosterone (11-KT) production by spermatogenic testicular tissue in coho salmon (Planas \& Swanson 1995). In contrast, only LH stimulates in vitro production of the maturationinducing steroid, 17 $17,20 \beta$-dihydroxy-4-pregnen-3-one 
(DHP), by the mature follicles of salmonids (Suzuki et al. 1988b, Planas et al. 2000) and the induction of germinal vesicle breakdown in mature oocytes of red seabream (Kagawa et al. 1998). However, data on unique function of FSH are limited to date, i.e. in vitro uptake of vitellogenin (VTG), recruitment of oocytes into vitellogenesis in rainbow trout, O. mykiss (Tyler et al. 1991, 1997), and proliferation of spermatogonia in rainbow trout (Loir 1999).

Recently, the fish GTH receptors (FSH-R and LH-R) were characterized in amago salmon, O. rhodurus (Oba et al. 1999a,b), African catfish, Clarias gariepinus (Bogerd et al. 2001, Vischer \& Bogerd 2003), channel catfish, Ictalurus punctatus (Kumar et al. 2001a,b), and zebrafish, Danio rerio (Kwok et al. 2005, So et al. 2005). These piscine FSH-R and LH-R belong to the superfamily of G-protein-coupled receptors having large extracellular domains, which contribute to ligand binding specificity (Kumar \& Trant 2001, Bogerd et al. 2005). Although, the fish FSH and LH receptors could be responding to their cognate ligands in vitro, the ligand binding specificity showed some different characteristics among fish species. FSH purified from chum salmon stimulated cAMP production in mammalian cells expressing both types of amago salmon GTH receptors, with a slight preference for FSH-R, whereas LH stimulated only LH-R (Oba et al. $1999 a, b)$. In the responsiveness of African catfish and zebrafish receptors, however, both FSH and LH elevated cAMP levels in FSH-R-expressing HEK-T 293 cells, whereas LH-R was activated by LH only (Bogerd et al. 2001, Vischer et al. 2003, Kwok et al. 2005, So et al. 2005). Specific interactions between GTHs and their receptors remain to be elucidated in other fish species.
In salmonids, our knowledge of the physiology of teleost GTHs has advanced considerably with the availability of purified GTHs (Suzuki et al. 1988a,b) and cloned GTH receptors (Oba et al. 1999a,b). Despite the numerous studies on the activities of purified fish GTHs or LH only in the past two decades, we are still far from understanding in depth the biological functions and mechanisms of the GTHs in regulating fish reproduction. In the present study, to clarify distinct biological function of salmon FSH and LH, we produced recombinant FSH and $\mathrm{LH}$ of a salmon species, Manchurian trout (Brachymystax lenok) in silkworm larvae as a bioreactor. The biological activities of the recombinant hormones were analyzed with respect to their potency to stimulate cAMP production in COS7 cells expressing amago salmon FSH-R or LH-R as well as steroidogenesis in vitro and in vivo. In addition, we examined temporal inducing potencies of the recombinant GTHs for milt production activity in goldfish.

\section{Materials and methods}

\section{Constructs of single-chain FSH and LH}

Gene-specific primers (Table 1) flanking the open reading frame $(\mathrm{ORF})$ of the Manchurian trout $(B$. lenok) FSH (mtFSH) and LH (mtLH) were used to amplify the ORF of each subunit cDNA (Choi et al. $2005)$. The GenBank accession numbers for $\operatorname{mtGTH} \alpha$, $\operatorname{mtFSH} \beta$, and $\operatorname{mtLH} \beta$ are AY500248, AY515500, and AY515501 respectively. The schematic diagrams for constructions of the tethered single-chain $\operatorname{mtFSH} \beta / \alpha$ and $m \operatorname{tLH} \beta / \alpha$ are shown in Fig. 1. At first, the ORF regions of mature $\beta$ subunits encoding the $\mathrm{mtFSH} \beta$ (24 amino acids of signal sequence and 118 amino acids of

Table 1 Oligo primers used in the polymerase chain reactions

\section{$\underline{\text { Direction }}$ Sequence}

\begin{tabular}{|c|c|c|}
\hline \multicolumn{3}{|l|}{ Primer } \\
\hline \#1 & F & $5^{\prime}$ - GCGAATTCACCATGGACTGCACCCACTTAAAG- 3 ' \\
\hline \#2 & $\mathrm{R}$ & $5^{\prime}$ - TGTATGATGATGATGATGATGCCCTGCCCTCACTGGTGTCATC- $3^{\prime}$ \\
\hline \#3 & $\mathrm{F}$ & 5' - GGGCATCATCATCATCATCATACAGACTGCTGGTATGGCTGC- $3^{\prime}$ \\
\hline \#4 & $\mathrm{R}$ & $5^{\prime}$ - CTGAACCTGTCGCATTTGATCCACTCATTTCTAGTGGGTTTACTACG - 3 ' \\
\hline \#5 & F & $5^{\prime}$ - AGTGGATCAAATGCGACAGGTTCAGGTTCTAACGCCACTTCAGGTTCTTATC \\
\hline \#6 & $\mathrm{R}$ & 5' - CCGCTCGAGTTAATGATGATGATGATGATGTGATTTATGGTA- 3 ' \\
\hline \#7 & F & 5' -GCGAATTCACCATGGTAGGTCTTCATGTAGG - 3 ' \\
\hline \#8 & $\mathrm{R}$ & $5^{\prime}$ - GAGATGATGATGATGATGATGAGACCCCTCAACGGGTTCCAG- $3^{\prime}$ \\
\hline \#9 & F & $5^{\prime}$ - TCTCATCATCATCATCATCATCTCATGCAGCCCTGTCAGCCC- $3^{\prime}$ \\
\hline \#10 & $\mathrm{R}$ & $5^{\prime}$ - CTGAACCTGTCGCATTTGATCCACTCCACATGTCACCATCCGTTA- 3 ' \\
\hline
\end{tabular}

$\mathrm{F}$, forward; R, reverse; underline = restriction enzyme recognition sites; double-underline $=$ codon of $6 \times$ histidine; bold characters $=$ Kozak sequence; box $=$ $\mathrm{N}$-linked carbohydrate sequence. 
(a)

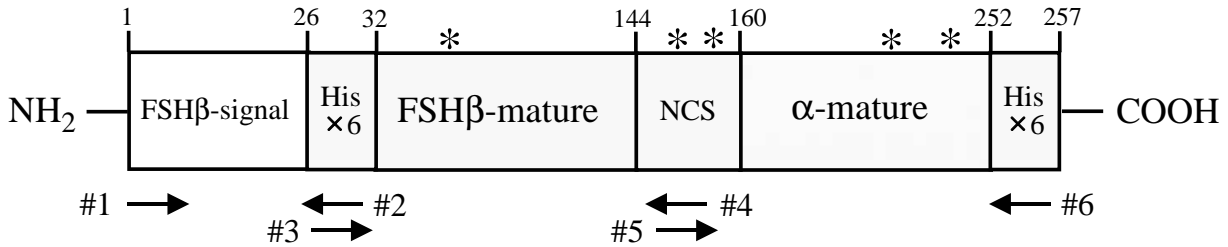

(b)

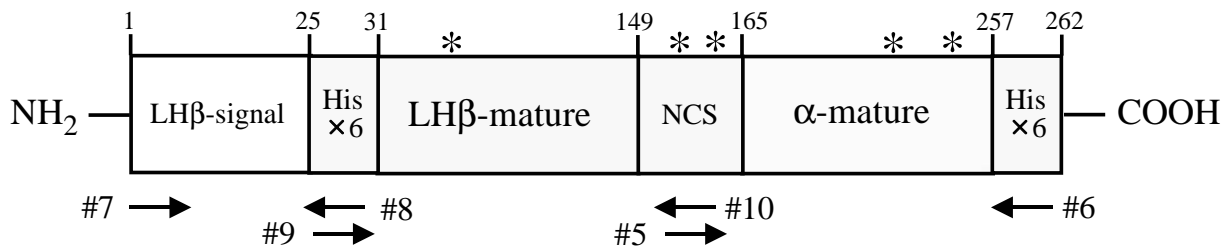

Figure 1 Schematic diagrams of recombinant single-chain Manchurian trout FSH (r-mtFSH) (a) and LH $(r-m t L H)(b)$. Primers (\#1-\#10) used for overlapping PCR strategy are listed in Table 1. The numbers above each box refer to the position of amino acids in each fragment or gonadotropin subunit. Asterisks above each box indicate the putative $N$-linked glycosylation sites (Asn-X-Ser/Thr).

the mature protein without stop codon) or the mtLH $\beta$ (23 amino acids of signal sequence and 124 amino acids of the mature protein without stop codon), and mature mtGTH $\alpha$ were generated by overlapping PCR method with designated primers (Fig. 1 and Table 1: \#1-4 for mtFSH $\beta$; \#5-6 for mtGTH $\alpha$; \#7-10 for mtLH $\beta$ ). Some substitutions were introduced in the primers to maximize the translation from predicted initiation site (\#1 and \#7) and to generate hexahistidinyl peptide (His-Tag; \#2-3 and \#8-9). In each cDNA construct, a synthetic DNA encoding Ser-Gly-Ser-Asn-Ala-Thr-GlySer-Gly-Ser-Asn-Ala-Thr-Ser-Gly-Ser ( $N$-linked glycosylation sequence (NCS); \#4-5 and \#10) was inserted between the $\beta$ and $\alpha$ chain by overlapping PCR strategy, since a recombinant human FSH containing the NCS was defined as a longer-acting agonist than native FSH (Klein et al. 2003). In addition, an Eco RI site was placed at the $5^{\prime}$-end of the DNA constructs and an Xho I site immediately following the terminator codon of the common GTH $\alpha$ subunit. PCR was performed in $50 \mu \mathrm{l}$ final volume containing the subunit cDNA templates (Choi et al. 2005), $5 \mu \mathrm{l} 10 \times$ reaction buffer, $2 \mathrm{mM}$ $\mathrm{MgCl}_{2}, 200 \mu \mathrm{M} \mathrm{dNTP}, 2 \mu \mathrm{M}$ each primer, and 2.5 U LA Taq DNA polymerase (Takara Bio, Otsu, Shiga, Japan). After an initial 5 min denaturing step at $94^{\circ} \mathrm{C}, 30$ cycles of amplification were performed using a cycle profile of $94{ }^{\circ} \mathrm{C}$ for $30 \mathrm{~s}, 55^{\circ} \mathrm{C}$ for $30 \mathrm{~s}$, and $72^{\circ} \mathrm{C}$ for $1.0 \mathrm{~min}$. After the last cycle, elongation was extended to $10 \mathrm{~min}$ at $72{ }^{\circ} \mathrm{C}$. Next, the PCR products were cut with Eco RI and Xho I, purified by gel-extraction and inserted into Eco RI-Xho I sites of a transfer vector (pYNG: Katakura Industries, Sayama, Saitama, Japan). Finally, the plasmid DNA was sequenced in both strands by chaintermination method using a Big Dye Terminator Ready Reaction Mix (Applied Biosystems, Boston, MA, USA) and an Applied Biosystems' Prism 377 DNA Sequencer.

\section{Production of recombinant $\mathrm{mtFSH}$ and $\mathrm{mtLH}$}

Recombinant Manchurian trout FSH (r-mtFSH) and LH (r-mtLH) were produced by the Superworm System (Katakura Industries), as previously described (Kobayashi et al. 2006). Briefly, the pYNG transfer vector harboring mtFSH or mtLH cDNA and baculovirus (Bombyx mori nucleopolyhedrovirus; CPd strain) genomic DNA were cotransfected into B. mori culture cells (BmN: Maeda 1989). Recombinant viruses, into which $\mathrm{mtFSH}$ and mtLH cDNAs were introduced by homologous recombination, were screened by the end-point dilution method on 96-well microplates (Maeda 1989). After propagation of the recombinant baculoviruses in B. mori culture cells, the recombinant baculovirus carrying cDNA of the $\mathrm{mtFSH}$ or mtLH was infected into silkworm larvae of the fifth instar early stage. The infected silkworm larvae were reared by artificial diet at $25^{\circ} \mathrm{C}$. Six or seven days after inoculation, hemolymph of the larvae containing r-mtFSH or r-mtLH was collected and centrifuged at $100000 \mathrm{~g}$ for $1 \mathrm{~h}$. The supernatants (approximately. $30 \mathrm{ml}$ per each recombinant protein) were stored at $-80^{\circ} \mathrm{C}$ until analysis.

\section{Protein purification and de- $\mathrm{N}$-glycosylation}

Histidine-tagged hormones were purified by Ni-NTA agarose beads (Qiagen) following the manufacturer's instructions. Briefly, a $50 \%$ suspension of the beads $(500 \mu \mathrm{l})$ was added to a sample tube containing $5 \mathrm{ml}$ hemolymph supernatant and incubated on a shaker at $4{ }^{\circ} \mathrm{C}$ for $2-3 \mathrm{~h}$. The beads were centrifuged briefly and supernatant was removed at $4{ }^{\circ} \mathrm{C}$. The remaining beads were packaged in a plastic column and washed with $10 \mathrm{ml}$ washing buffer $\left(50 \mathrm{mM} \mathrm{NaH}_{2} \mathrm{PO}_{4}, 300 \mathrm{mM} \mathrm{NaCl}\right.$, $20 \mathrm{mM}$ imidazole and $0.05 \%$ Tween $20, \mathrm{pH} 8 \cdot 0$ ) twice. The Ni-affinity proteins were then eluted with $900 \mu \mathrm{l}$ 
elution buffer $\left(50 \mathrm{mM} \mathrm{NaH}{ }_{2} \mathrm{PO}_{4}, 300 \mathrm{mM} \mathrm{NaCl}\right.$, $500 \mathrm{mM}$ imidazole and $0.05 \%$ Tween $20, \mathrm{pH} 8 \cdot 0$ ). To remove excessive salt and imidazole, the eluted samples $(300 \mu \mathrm{l})$ were centrifuged at $4{ }^{\circ} \mathrm{C}$ for $30 \mathrm{~min}$ with a centrifugal filter device (Amicon 10000 MWCO, Millipore Corp. Bedford, MA, USA). The filter device was washed with $300 \mu \mathrm{lBS}$ (PBS, $\mathrm{pH} 7 \cdot 6$ ) twice, and each recombinant hormone was finally eluted with the same volume of PBS and kept at $4{ }^{\circ} \mathrm{C}$. Protein concentration was measured by a spectrophotometer (Ultrospec3100pro, Amersham Biosciences) at $595 \mathrm{~nm}$ using a Bradford reagent (Sigma-Aldrich).

$N$-linked glycosylation state of the recombinant proteins was examined with $\mathrm{N}$-glycosidase F (PNGase F; Sigma-Aldrich) according to the instructions of the manufacturer and our recent report (Shin et al. 2006). Briefly, an aliquot $(10 \mu \mathrm{l})$ of the eluted samples was added to $10 \mu \mathrm{l}$ denaturing buffer consisting of $0.45 \%$ SDS, $1 \mathrm{M}$ Tris- $\mathrm{HCl}(\mathrm{pH} 8 \cdot 0)$, and $0 \cdot 1 \mathrm{M}$ 2-mercaptoethanol. The resulting solution was heated at $100{ }^{\circ} \mathrm{C}$ for $5 \mathrm{~min}$ and cooled on ice. Next, 1, 5, or $25 \mathrm{mU}$ PNGase $\mathrm{F}$ were added to this solution, followed by incubation at $37^{\circ} \mathrm{C}$ for $16 \mathrm{~h}$. Finally, the reaction mixture was applied to western blotting.

\section{Electrophoresis and western blot analysis}

SDS-PAGE was performed using $12.5 \%$ polyacrylamide gels and proteins were transferred to a nitrocellulose membrane (Pall Corp., Ann Arber, MI, USA). After blocking, the membrane was sequentially incubated in a ratio of 1:2000 dilution of polyclonal rabbit antibodies (anti-goldfish GTH $\alpha$, Kobayashi et al. 2006; anti-His-Tag, Santa Cruz Biotech., Santa Cruz, CA, USA) overnight at $4^{\circ} \mathrm{C}$ and a peroxidase-conjugated polyclonal antibody to rabbit IgG (1:2000; Santa Cruz Biotech.) for $2 \mathrm{~h}$ at room temperature. After washing, the membrane was incubated in a chemiluminescent detection reagent (Amersham Biosciences) according to the manufacturer's directions and bands were visualized by exposure to X-ray film (Amersham Biosciences).

\section{In vitro cAMP assay}

Ligand-stimulated intracellular cAMP production was examined by cAMP responsive reporter and enzymeimmunoassay (EIA) system using COS-7 cells transiently transfected with amago salmon FSH-R or LH-R expression plasmid (Oba et al. 1999a,b; kind gifts from Dr Yoshitaka Nagahama, National Institute for Basic Biology, Okazaki, Aichi, Japan). COS-7 cells were maintained at $37^{\circ} \mathrm{C}$ with $5 \% \mathrm{CO}_{2}$ in Dulbecco's modified Eagle's medium containing 10\% heatinactivated fetal bovine serum (FBS) and $1 \%$ antibiotic-antimycotic reagent (GIBCO, Invitrogen).
Approximately, $5 \times 10^{4}$ cells were cultured in 24-well plates and transfection was performed using the Lipofectamine 2000 reagent (Invitrogen) according to the manufacturer's instructions. In the reporter gene assay, $200 \mathrm{ng}$ of each receptor expression plasmid and pCRE-luciferase reporter plasmid containing four copies of the cAMP response element (Stratagene, La Jolla, CA, USA) along with a LacZ expression vector, $\mathrm{pRSV}-\beta$-galactosidase (internal control plasmid) were cotransfected into the cells. About $24 \mathrm{~h}$ after transfection, the cells were changed into fresh medium supplemented with 10\% FBS and treated with r-mtFSH or r-mtLH. After $6 \mathrm{~h}$ hormone treatment, the cells were subsequently washed with ice-cold PBS and lysed with $100 \mu \mathrm{l} 1 \times$ lysis buffer (Promega). Luciferase activity was measured with an assay buffer ( $1 \mathrm{mM}$ luciferin, $2 \cdot 16 \mathrm{mM}$ ATP, $10 \cdot 8 \mathrm{mM}$

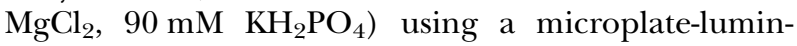
ometer (EG\&G Berthold, Bad Wildbad, Germany) and normalized by the $\beta$-galactosidase values. Transfection experiments were performed in triplicate and repeated at least twice. In measuring the intracellular cAMP concentration, the cells transiently transfected with $200 \mathrm{ng}$ FSH-R or LH-R plasmid as mentioned above were lysed and applied to BIOTRAK cAMP EIA system (Amersham Biosciences) according to the manufacturer's instructions.

\section{In vitro sex steroid production by rainbow trout follicles}

The experimental fish were kindly provided by Salmon Research Center, East Sea Fisheries Research Institute, Yang-Yang, Gangwon-do, Korea. In December 2004, ovarian follicles from one sexually mature female rainbow trout (gonadosomatic index (GSI; gonad weight $\times 100 /$ body weight), $17.9 \%)$ and one maturing female (GSI, 12.6\%) were used in the present experiment. Following decapitation, ovaries were immediately dissected and kept in ice-cold HEPES-NaOH-buffered trout balanced-salt solution (TBSS; $\mathrm{pH} 7 \cdot 5$ ) according to the methods of Kagawa et al. (1982). The ovarian follicles were incubated in 24-well culture plates containing $1 \mathrm{ml}$ of TBSS ( 5 or 10 follicles/well) with various doses of $\mathrm{r}$-mtGTHs in a humidified incubator at $15^{\circ} \mathrm{C}$ for $18 \mathrm{~h}$. The incubated media were collected and kept at $-20^{\circ} \mathrm{C}$ until RIA for steroid hormones.

\section{In vivo effects of r-mtGTHs on female rainbow trout}

In February 2005, 1-year-old immature rainbow trout (average body weight (BW), $201 \pm 10 \mathrm{~g}$; average GSI, $0 \cdot 05 \pm 0 \cdot 01$ ), which were reared in fresh water of a raceway tank (Salmon Research Center, Yang-yang, Korea), were anesthetized with 2-phenoxyethanol $(0.5 \mathrm{ml} / \mathrm{l})$ 
and randomly assigned to one of three treatment groups ( $n=7$ per group): hemolymph-derived Ni-affinity proteins (negative control), r-mtFSH, or r-mtLH. All proteins were diluted to a concentration of $80 \mu \mathrm{g} / \mathrm{ml}$ PBS containing BSA $(1 \mathrm{mg} / \mathrm{ml})$. Hormone was administered as a single i.p. injection at a dose of $10 \mu \mathrm{g} / 100 \mathrm{~g}$ BW. Blood samples were collected from the fish 18, 24, and $72 \mathrm{~h}$ after the injection, taken from the caudal vasculature with a heparinized syringe and needle after anesthetization with 2-phenoxyethanol. Blood samples were centrifuged at $4000 \mathrm{~g}$ and plasma was stored at $-80^{\circ} \mathrm{C}$ until RIA. The fish were killed 72 -h postinjection by decapitation and body as well as gonad weights were recorded. Parts of the gonads were fixed in $50 \mathrm{ml}$ Bouin's solution for $24 \mathrm{~h}$ over night and then processed in ascending concentrations of alcohol, embedded in paraffin, and sectioned at a thickness of $7 \mu \mathrm{m}$ on a rotary microtome. Every section at intervals of $100 \mu \mathrm{m}$ was mounted on a microscope slide and stained with hematoxylin-eosin solution. To examine the effects of recombinant hormones on ovarian follicles in vivo, all the ovarian section were viewed with a light microscope (Olympus CX31, Shinjuku, Tokyo, Japan) and follicle diameters were measured in the order of larger size $(n=$ 10 ; each fish) without repeated measurements.

\section{RIA}

Concentrations of $\mathrm{T}$ and $\mathrm{E} 2$ in the medium or blood plasma were measured by RIAs as previously described (Aida et al. 1984, Kobayashi et al. 1988). Rabbit anti-E26-CMO-BSA and anti-T-6-CMO-BSA sera were purchased from Cosmo-Bio Co. Ltd (Koto, Tokyo, Japan). Non-radioactive steroids to be used as standards were purchased from Steraloids Inc. (Wilton, NH, USA). Radio-labeled $\mathrm{T}$ and $\mathrm{E} 2$ $\left(\left[2,4,6,7-{ }^{3} \mathrm{H}\right]-\mathrm{T}\right.$ and $\left.\left[2,4,6,7-{ }^{3} \mathrm{H}\right]-\mathrm{E} 2\right)$ were purchased from Amersham Biosciences.

The sensitivities of the assays were $12.5 \mathrm{pg} / \mathrm{ml}$ and $10 \mathrm{pg} / \mathrm{ml}$ for E2 and Trespectively. The intra- and interassay coefficients of variations at the $50 \%$ binding were $3.4 \%(n=3)$ and $11.5 \%(n=6)$ for $\mathrm{E} 2,2 \cdot 3 \%(n=3)$ and $12.5 \%(n=6)$ for $\mathrm{T}$ respectively. The cross-reactions of $\mathrm{E} 2$ antibody to estrone and estriol were 0.5 and $0.9 \%$ respectively. Cross-reactivities with Tand DHP in the E2 measurement were $<0.01 \%$. The $\mathrm{T}$ antibody crossreacted with dihydrotestosterone $(2 \cdot 7 \%)$, androsten3,17-dione $(0.5 \%), 11$-KT $(0.5 \%)$ and androstenedione $(0 \cdot 35 \%)$, and all other steroids tested showed $<0 \cdot 001 \%$.

\section{Bioassays for milt production}

The milt production in male goldfish by the $\mathrm{r}-\mathrm{mtFSH}$ or r-mtLH was examined according to a previous report (Kobayashi et al. 2006). Briefly, in the milt production assay, sexually mature spermiated male goldfish (average BW, 14.6 g) were starved for 710 days to suppress milt production and then injected with hemolymph containing recombinant hormones. Milt production of the experimental fish was examined $24 \mathrm{~h}$ after injection by gentle stroking of the abdomen.

\section{Statistical analysis}

All data were expressed as the mean \pm s.E.M. Statistical significance was determined by one-way ANOVA followed by Duncan's multiple-range test $(P<0 \cdot 05)$.

\section{Results}

\section{Production of recombinant Manchurian trout GTHs}

To study the biological activities and physiological significances of the two GTHs in the Manchurian trout, we produced recombinant Manchurian trout GTHs using baculovirus-silkworm larvae system as a bioreactor. In a SDS-PAGE analysis, a specific band corresponding to a molecular size of approximately $35 \mathrm{kDa}$ for $\mathrm{r}-\mathrm{mtFSH}$ or $38 \mathrm{kDa}$ for $\mathrm{r}-\mathrm{mtLH}$ was shown in the Ni-affinity fraction from hemolymph of silkworm larvae that were infected with the recombinant baculovirus carrying mtFSH or mtLH cDNA (Fig. 2a). Based on spectrophotometeric absorbance and protein moiety in SDS-PAGE, the purified recombinant hormones were calculated to 60 and $180 \mu \mathrm{g}$ per larva for the r-mtFSH and r-mt-LH respectively. In contrast, there were no equivalent bands at 35 and $38 \mathrm{kDa}$ in the fraction from non-infected silkworm hemolymph. Furthermore, western blot analysis using a goldfishGTH $\alpha$ antibody confirmed that the 35 and $38 \mathrm{kDa}$ molecules are the r-mtFSH and the r-mtLH (Fig. 2b). In addition, anti-His-Tag probe detected the same bands in a western blot (Fig. 2c).

To examine $N$-linked glycosylation states of the $\mathrm{r}$-mtFSH and the r-mtLH, the purified hormones were incubated with PNGase $\mathrm{F}$ at $37^{\circ} \mathrm{C}$ for $16 \mathrm{~h}$ and the resulting reactants were applied to western blot by the goldfish GTH $\alpha$ antibody. After digestion with the enzyme, the recombinant proteins decreased in molecular mass to 31-33 kDa as shown in Fig. 2d.

\section{In vitro cAMP production assays}

The functional characteristics of the r-mtFSH and r-mtLH were investigated using the COS-7 cells transiently transfected with salmon GTH-R expression plasmid, cAMP responsive reporter (CRE-luc), and EIA systems. In the CRE-luc examination, luciferase expression was significantly and selectively activated in 
(a)

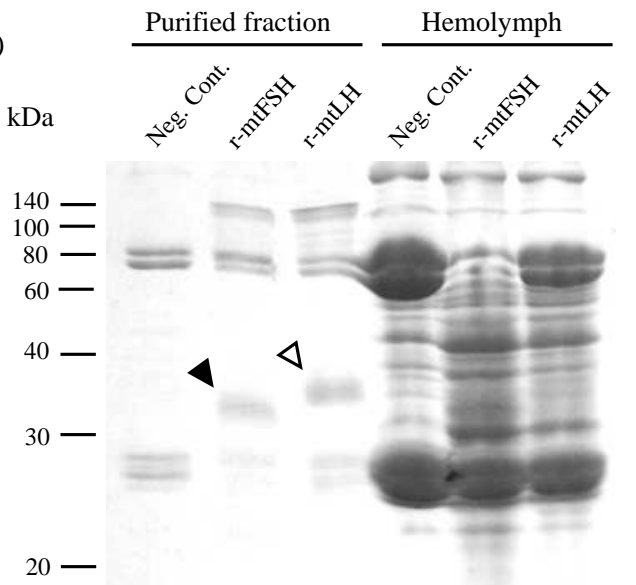

(b)

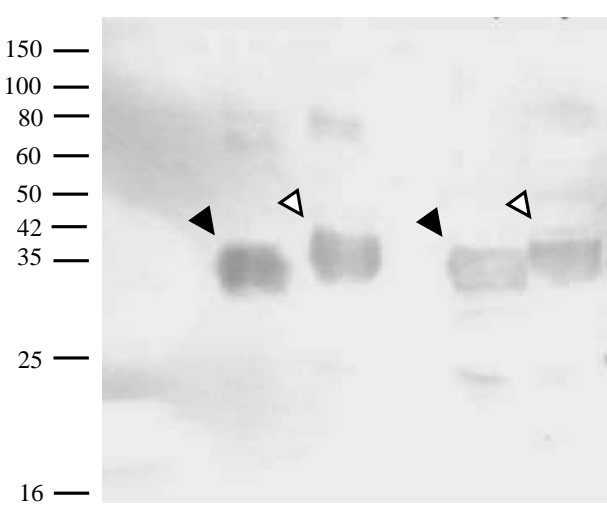

(c)

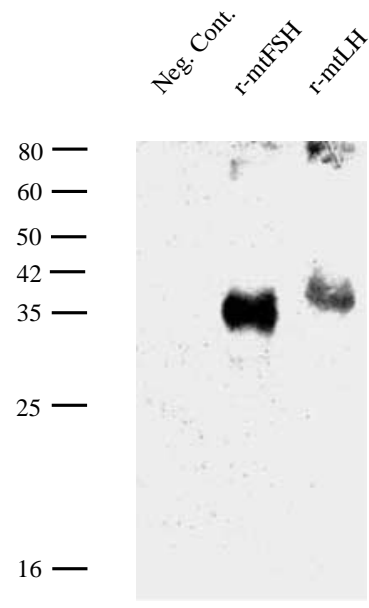

(d)

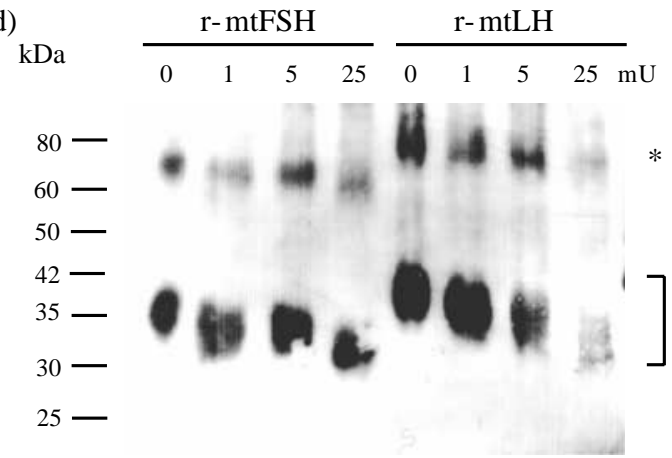

Figure 2 SDS-PAGE, western blot, and de- $N$-glycosylation analyses of recombinant Manchurian trout FSH $(r-m t F S H)$ and LH (r-mtLH). (a) SDS-PAGE (12.5\%) was conducted under reducing conditions with hemolymph of silkworm or $\mathrm{Ni}$-affinity purified fraction as indicated. (b) r-mtFSH and r-mtLH were detected by SDS-PAGE (12.5\%) under reducing conditions followed by western blot using an anti-goldfish GTH $\alpha$ antibody. Black and white arrow heads in (a) and (b) indicate r-mtFSH and r-mtLH bands respectively. (c) Western blot using an antibody for His-Tag. (d) Purified r-mtFSH and $\mathrm{r}$-mtLH were incubated at $37^{\circ} \mathrm{C}$ for $16 \mathrm{~h}$ without or with increasing amounts of PNGase $\mathrm{F}$ treatments $(1-25 \mathrm{mU})$, followed by western blot using the goldfish GTH $\alpha$ antibody. Non-specified bands are indicated by an asterisk.

the FSH-R-expressing cells by the r-mtFSH and in the LH-R-expressing cells by the r-mtLH respectively, in dose-dependent manners (Fig. 3a), but the response of the latter was much more potent. In the EIA system, cAMP production levels in response to the r-mtFSH or r-mtLH also increased in the cognate receptor-transfected cells, and hCG $(5 \mu \mathrm{g} / \mathrm{ml})$ stimulated the cAMP production in LH-R-cells only (Fig. 3b).

\section{In vitro effects of r-mtGTHs on sex steroid production}

To investigate steroidogenic actions of the r-mtFSH and the r-mtLH in salmonid ovary, we examined the steroidogenic response of rainbow trout intact follicles at two different stages of oocyte maturation. In fullgrown follicles from a mature female $(\mathrm{GSI}=17 \cdot 9)$, the production of $\mathrm{E} 2$ and $\mathrm{T}$ was significantly stimulated by the r-mtFSH and r-mtLH respectively, at a dose of $100 \mathrm{ng} / \mathrm{ml}$ (Fig. 4a). In contrast, E2 and T increased by growing follicles from a maturing female $(\mathrm{GSI}=12 \cdot 6)$ in response to both recombinant hormones at higher doses $(1 \mu \mathrm{g} / \mathrm{ml}$; Fig. $4 \mathrm{~b})$.

\section{In vivo effects of r-mtGTHs on ovarian development in female rainbow trout}

Mean GSI and follicle diameter following a single injection of control protein, r-mtFSH or r-mtLH in immature rainbow trout are shown in Fig. 5a. The injection of r-mtFSH, but not r-mtLH, increased mean GSI and follicle diameters significantly as compared with those of control fish, although the r-mtLH slightly increased GSI value. In histological examination, vitellogenic follicles at early stages (cortical alveoli 

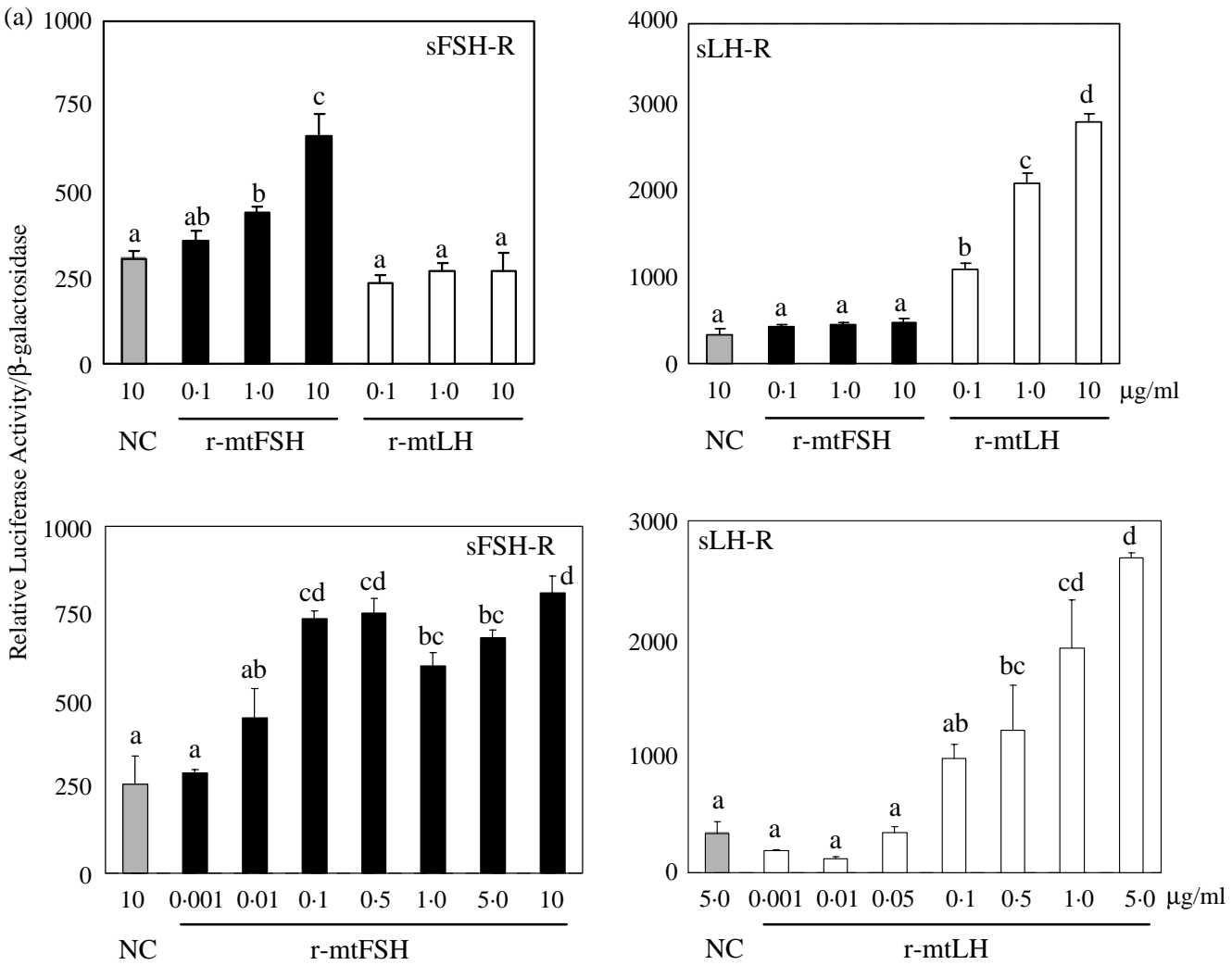

(b)
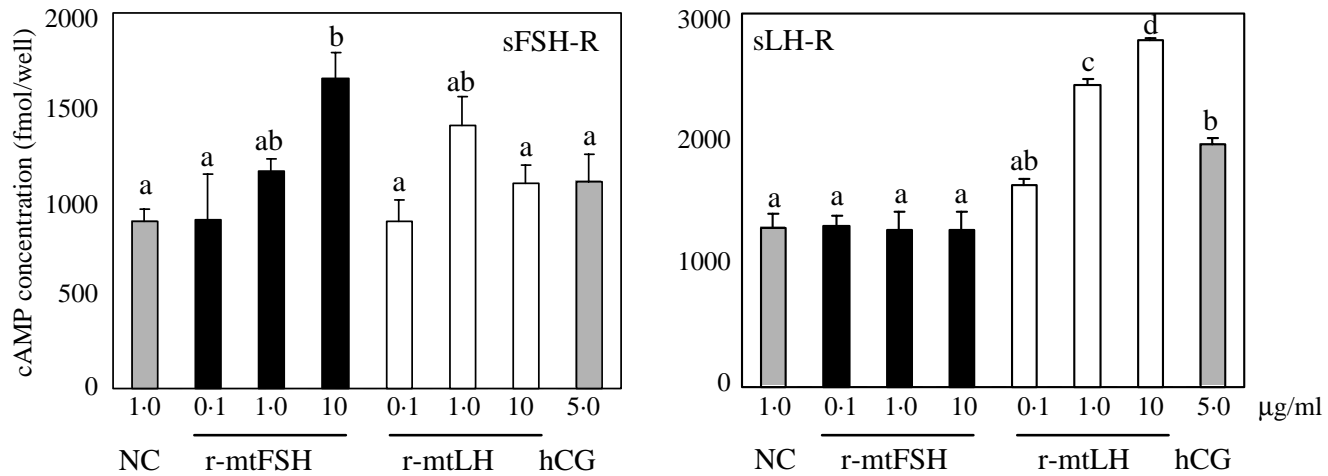

Figure 3 In vitro biological activities, as assessed by cAMP production, of r-mtFSH and r-mtLH. (a) Effects of r-mtFSH and r-mtLH on COS-7 cells transiently cotransfected with a cAMP-responsive reporter gene construct (pCRE-luciferase) and amago salmons FSH-R or LH-R. (b) Intracellular cAMP concentration in COS-7 cells transiently transfected with amago salmon FSH-R or LH-R (EIA method). NC, negative control. Values sharing the same letter do not significantly differ $(P<0 \cdot 05)$.

and/or oil droplet stages) were frequently observed in the ovaries of r-mtFSH-injected fish (Fig. 5a), whereas ovaries in control and r-mtLH-injected fish did not contain these stages of follicles. Plasma levels of E2 fish receiving the $\mathrm{r}-\mathrm{mtFSH}$ were also elevated from 18-h post-injection and attained maximum levels at $24 \mathrm{~h}$ (Fig. 5b). At 72-h post-injection, E2 levels still showed higher concentration in the r-mtFSH-injected fish when compared with those of control and r-mtLH-injected fish, but significant differences were not observed among the three groups. In r-mtLH-treated fish, plasma $\mathrm{T}$ levels and mean GSI values were not significantly different from those of control fish, although these parameters showed a tendency to increase. 
(a) $\quad$ GSI $=17 \cdot 9$

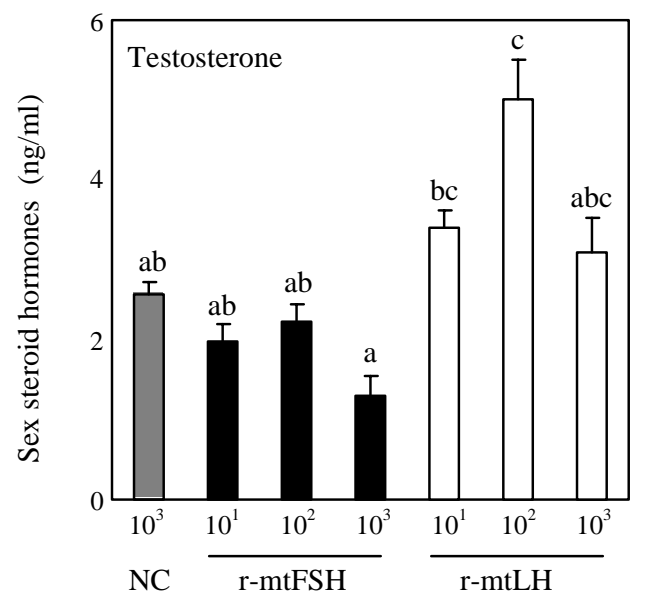

(b) $\quad$ GSI $=12 \cdot 6$

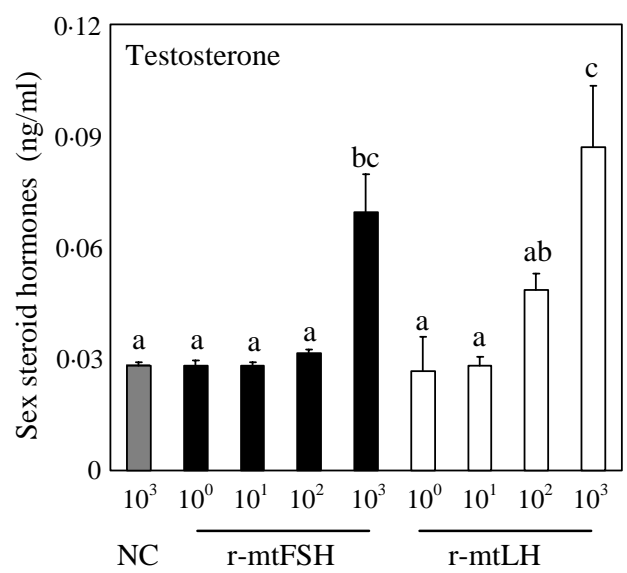

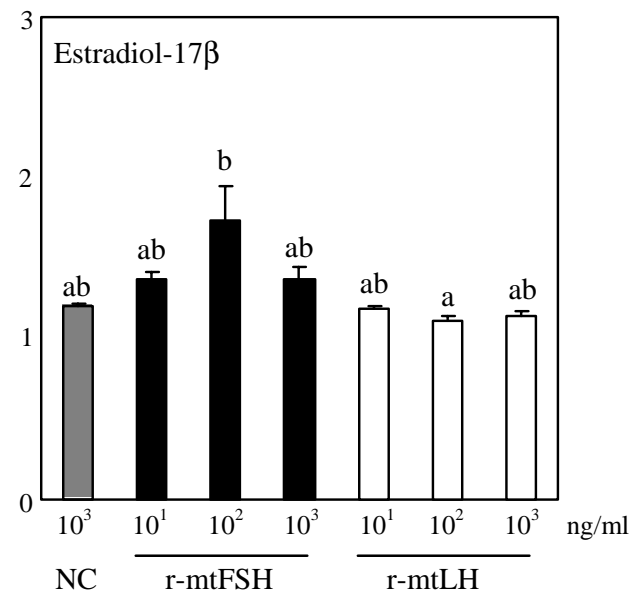

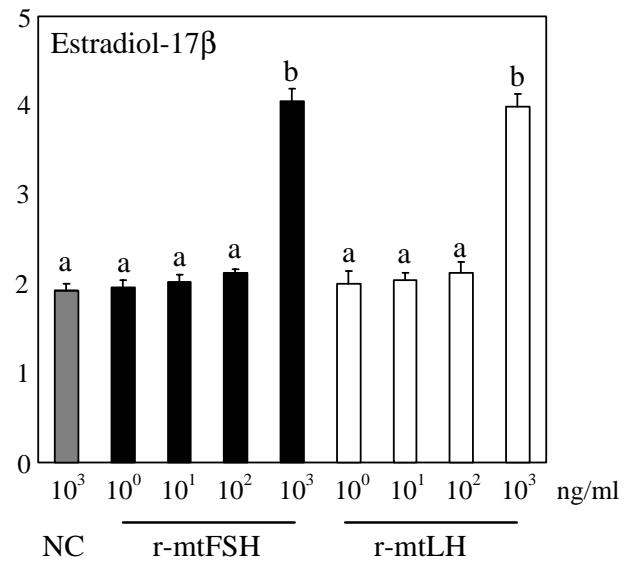

Figure 4 Effects of $r-m t F S H$ and $r-m t L H$ on testosterone $(T)$ and estradiol-17 $\beta$ (E2) production in vitro by intact ovarian follicles from sexually mature (a) and maturing sfemale rainbow trout (b). The ovarian follicles were incubated in 24-well culture plates containing $1 \mathrm{ml}$ of HEPES-NaOH-buffered trout balanced-salt solution ( $\mathrm{pH} \mathrm{7.5)}$ with indicated doses of recombinant GTHs at $15^{\circ} \mathrm{C}$ for $18 \mathrm{~h}$. NC, negative control. Values sharing the same letter do not differ significantly $(P<0.05)$.

\section{Milt production in goldfish}

Injection of hemolymph containing r-mtFSH or r-mtLH ( 5 or $20 \mu \mathrm{l} / \mathrm{g}$ BW) induced milt production in male goldfish as did hCG (10 U/g BW; Table 2).

\section{Discussion}

In the present study, we demonstrated that (1) biologically-active recombinant Manchurian trout GTHs can be produced by a baculovirus-silkworm larvae system; (2) the recombinant hormones selectively activate their cognate receptors and produce sex steroids in ovarian follicles in vitro; and (3) the hormones have the potency to stimulate steroidogenesis and ovarian development of rainbow trout in vivo, and these are effective for milt production in goldfish. This is the first report on production of biologically active recombinant GTHs in salmonids, although pioneering researches on the fish GTHs and GTH receptors were carried out using salmon species (Suzuki et al. 1988a,b, Yan et al. 1992, Miwa et al. 1994, Oba et al. 1999a,b).

In order to produce heterodimeric and biologically active recombinant GTHs, single-chain mtFSH and $\mathrm{mtLH}$ were constructed in which the carboxyl terminus of the $\mathrm{mtFSH} \beta$ or $\mathrm{mtLH} \beta$ subunit was fused to the amino terminus of the mature mtGTH $\alpha$ subunit with an intermediate polypeptide sequence (NCS). In mammals, a recombinant human FSH containing the NCS extended half-life in the blood by $7 \cdot 3 \mathrm{~h}$, which is twofold longer than native recombinant FSH (Klein et al. 2003). 
$\mathrm{GSI}=0 \cdot 05 \pm 0 \cdot 01$

(a)
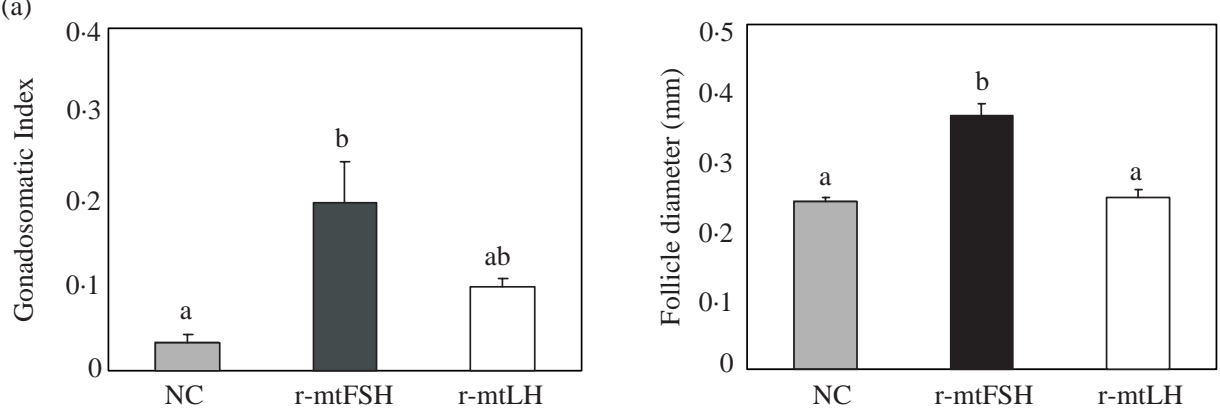

$250 \mu \mathrm{m}$
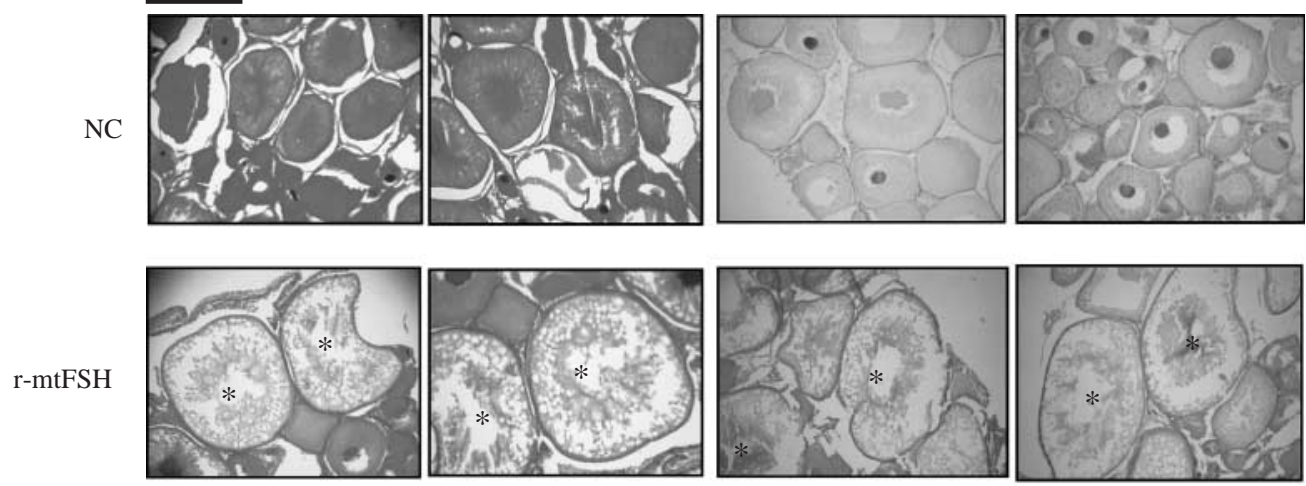

r-mtLH
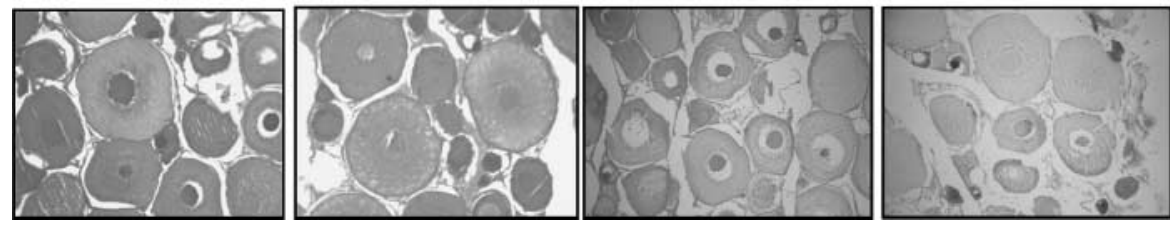

(b)
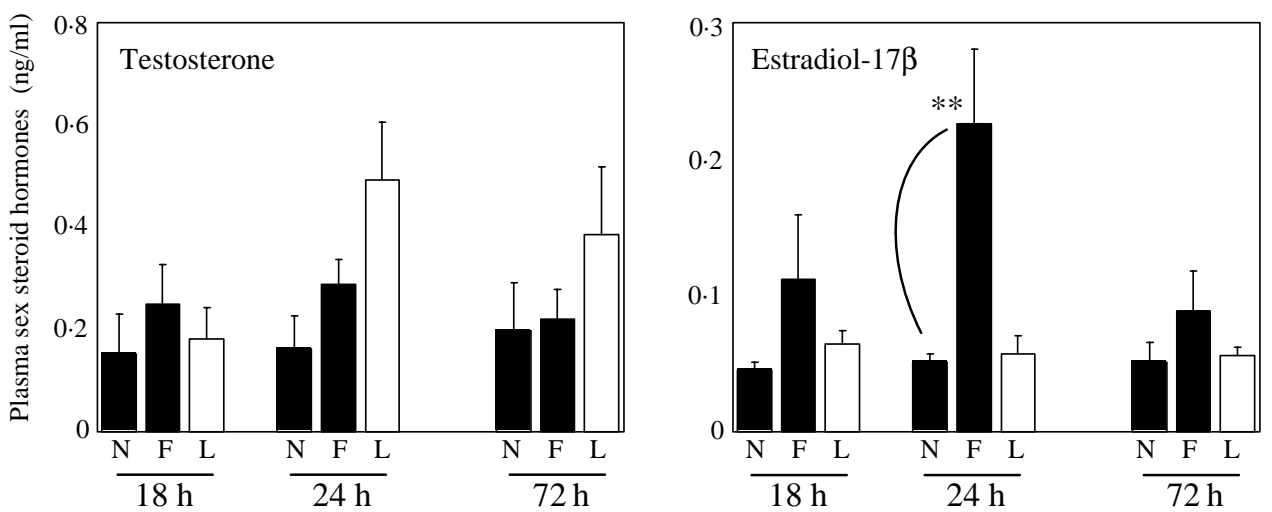

Figure 5 In vivo effects of $\mathrm{r}-\mathrm{mtFSH}$ and $\mathrm{r}$-mtLH on ovarian development (a) and sex steroid hormone production (b) in sexually immature female rainbow trout. r-mtFSH or r-mtLH was administered as a single i.p. injection at a dose of $10 \mu \mathrm{g} / 100 \mathrm{~g} \mathrm{BW}$. Blood samples were collected at 18, 24, and 72-h post-injection and plasma sex steroid levels were measured by RIA. The ovaries were weighed for GSI calculation and a part of the ovary was individually fixed in Bouin's solution for histological examination (H\&E staining).

Single asterisk and double asterisks indicate vitellogenic follicles at early stages and significant differences at $P<0.01$ respectively. Values sharing the same letter do not differ significantly $(P<0.05)$. NC $(\mathrm{N})$, hemolymph of silkworm larvae as a negative control; F, r-mtFSH; L, r-mtLH. 
Table 2 Bioassays for r-mtFSH and r-mtLH inducing milt production in male goldfish

\begin{tabular}{|c|c|c|c|c|}
\hline & $\begin{array}{l}\text { No } \\
\text { response }\end{array}$ & $\begin{array}{l}\text { Milt } \\
\text { produced }\end{array}$ & $n$ & Dosage \\
\hline Silkworm hemolymph & 7 & 0 & 7 & $b$ \\
\hline$r-m t F S H$ & 1 & 6 & 7 & a \\
\hline r-mtFSH & 0 & 7 & 7 & $b$ \\
\hline$r-m t L H$ & 1 & 6 & 7 & a \\
\hline r-mtLH & 1 & 6 & 7 & $b$ \\
\hline hCG & 1 & 6 & 7 & c \\
\hline
\end{tabular}

a, $5 \mu \mathrm{l} / \mathrm{g}$ Body weight (BW); b, $20 \mu \mathrm{l} / \mathrm{g} \mathrm{BW}$;, $10 \mathrm{U} / 20 \mu \mathrm{l} / \mathrm{g} \mathrm{BW} ; n$, fish number.

Binding potency of the NCS-FSH to the human FSH receptor and signal transduction was also comparable with those of native FSH. In the present investigation, SDS-PAGE followed by western blot analyses using antibodies for both goldfish GTH $\alpha$ subunit and HisTag revealed that the tethered $\mathrm{mtFSH} \beta / \alpha$ and $\operatorname{mtLH} \beta / \alpha$ proteins are successfully produced in the silkworm larvae. Furthermore, molecular masses of the r-mtFSH and r-mtLH corresponded to 35 and $38 \mathrm{kDa}$ respectively, indicating that the proteins were $\mathrm{N}$-glycosylated; if not both proteins should be detected as $29 \mathrm{kDa}$ molecules. In fact, an $\mathrm{N}$-glycosidase $\mathrm{F}$ treatment decreased the molecular masses of r-mtFSH and r-mtLH to 31 and $33 \mathrm{kDa}$ respectively, confirming their properties as glycoproteins. An extra and non-specified band at high molecular mass ranges $(70-80 \mathrm{kDa})$ was shown by the western blots. Although we have no clear explanation for these bands, these results may imply that unexpected dimerization occurred in the recombinant hormones, judged by their molecular sizes and glycosylated forms. The different molecular sizes between r-mtFSH and r-mtLH are most likely due to the different signal sequences of the proteins rather than $N$-linked moieties, since excessive treatments of $\mathrm{N}$-glycosidase $\mathrm{F}$ $(\sim 100 \mathrm{mU})$ did not change the molecular masses and evidently, the amino terminus of $\mathrm{r}-\mathrm{mtFSH}$ was started from mature $\operatorname{mtFSH} \beta$, whereas the r-mtLH had intact signal sequence of mtLH $\beta$ (data not shown). In a previous report, we noted that the different secretion pattern between recombinant $\mathrm{mtFSH}-$ and $\mathrm{mtLH}-$ expressing CHO cells may be due to the higher hydrophobicity of signal peptides in mtLH $\beta$ than that of mtFSH $\beta$ (Choi et al. 2005).

To date, several recombinant GTHs of fishes have been produced in various bioreactors, such as yeast (Kamei et al. 2003, Kasuto \& Levavi-Sivan 2005), transgenic fish (Morita et al. 2004), soil amoeba (Vischer et al. 2003), S2 Drosophila cell line (Zmora et al. 2003), CHO cells (Choi et al. 2005, So et al. 2005), and silkworm larvae (Kobayashi et al. 2006). Although goldfish recombinant GTHs produced in silkworm larvae (Kobayashi et al. 2006) were characterized as biologically active hormones, information of the direct effects of recombinant GTHs to their cognate receptors is essential to examine the function of r-mtFSH and $\mathrm{r}$-mtLH. Evaluation of the binding properties of r-mtFSH and r-mtLH to amago salmon GTH receptors and signal transduction in vitro was conducted by intracellular cAMP productivities using a cAMP responsible reporter and a direct EIA assay. In both systems, r-mtFSH and r-mtLH were highly specific for their cognate receptors, but the r-mtLH:LH-R interaction was potent in terms of signal transduction when compared with that of the r-mtFSH:FSH-R. It is noteworthy that magnitude of the LH interaction with LH-R was greater than that of FSH to FSH-R in both the Manchurian trout and chum salmon (Oba et al. $1999 a, b)$. Opposite to the situation in the salmon species, however, the African catfish FSH responded to the cognate FSH-R with higher potency $\left(\mathrm{EC}_{50}\right.$ : $0 \cdot 31 \mathrm{ng} / \mathrm{ml}$ ) than that of African catfish $\mathrm{LH}$ to the LH-R (EC ${ }_{50}: 26 \cdot 76 \mathrm{ng} / \mathrm{ml}$; Vischer et al. 2003). In contrast to the high specificity of r-mtFSH and r-mtLH for their receptors, purified chum salmon FSH activated both types of GTH receptors with a slight preference for FSH-R, while LH did only LH-R (Oba et al. $1999 a, b)$. In in vitro ligand autoradiography, coho salmon FSH showed a specific interaction with FSH-R, whereas LH interacted with both FSH-R and LH-R (Miwa et al. 1994), which is a similar situation in African catfish (Vischer et al. 2003), channel catfish (Zmora et al. 2003), and zebrafish (So et al. 2005). Although we have no clear explanation for these different observations, these results may be attributed to high plasticity of gonadotropin-receptor interaction in teleosts and the use of heterologous GTHs from a different species.

The biological activity of the recombinant $\mathrm{r}-\mathrm{mtFSH}$ and r-mtLH was further evaluated in steroidogenic effects on intact ovarian follicles of rainbow trout in vitro. As expected, both $\mathrm{r}-\mathrm{mtFSH}$ and $\mathrm{r}-\mathrm{mtLH}$ were capable of inducing $\mathrm{T}$ and $\mathrm{E} 2$ production in maturing ovarian follicles which are generally in agreement with the potency of purified FSH and LH in coho salmon (Planas et al. 2000), although the magnitude of steroidogenic effect of coho salmon FSH and LH was greater than that of r-mtFSH and r-mtLH effects on the maturing follicles. In fully grown follicles from mature rainbow trout, on the other hand, r-mtFSH but not $r$-mtLH had a weak stimulatory effect on E2 production, whereas only $\mathrm{r}-\mathrm{mtLH}$ stimulated the production of $\mathrm{T}$ at a dose of $100 \mathrm{ng} / \mathrm{ml}$. Considering that in red seabream gradually increased levels of aromatase mRNA during oocyte growth dramatically decreased in follicles at the migratory nucleus and the mature stages (Gen et al. 2001), no effect of r-mtLH on the E2 production by mature follicles of rainbow trout is at least in part, due to decreased aromatase expression level in the follicles. Further research is clearly needed to determine the 
precise activities of r-mtFSH and r-mtLH during final oocyte maturation in salmonids.

In the present study, biological activities of recombinant Manchurian trout FSH and LH were further examined with respect to their in vivo effects, i.e. ovarian development and production of sex steroids. In immature rainbow trout, a single injection with $r-m t F S H$ but not $r-m t L H$ significantly increased mean GSI and follicle diameters as compared with those of control fish, at 3 days post-injection. Furthermore, vitellogenic oocytes were frequently observed and plasma E2 levels at 24-h post-injection were significantly higher in the r-mtFSH-injected fish than in control fish. These data are consistent with a previous report that FSH but not LH function in stimulating in vitro and in vivo VTG uptake into vitellogenic follicles of rainbow trout within $24 \mathrm{~h}$ (Tyler et al. 1991). Moreover, E2 is also able to induce VTG mRNA expression, protein synthesis and release in juvenile rainbow trout within $48 \mathrm{~h}$ (Arukwe et al. 2001). Thus, it is strongly suggested that r-mtFSH elevated plasma E2 levels and in turn E2 stimulated VTG synthesis and to some extent its uptake into immature ovarian follicles of rainbow trout. Plasma T levels showed an increasing tendency by r-mtLH at 24and 72-h-post-injection, while E2 was not changed by the hormone throughout the examinations. These results suggest that the r-mtLH did not augment ovarian aromatase activity in immature rainbow trout. Recently, Kagawa's research group defined clearly the expression and activities of ovarian $\mathrm{P} 450$ aromatase, which are mainly controlled by LH but not FSH during oocyte development of red seabream (Gen et al. 2001, Kagawa $e t$ al. 2003). In the rainbow trout, however, FSHcontaining fraction but not LH-fraction was able to increase E2 production by early vitellogenic follicles in vitro, although highly purified GTHs were not used (Nagler \& Idler 1991). These results may in part be explained by differences of gonadal development patterns between rainbow trout, which undergoes synchronous ovarian development and red seabream having an asynchronous type of ovary.

In the bioassays for milt production in a heterogeneous species, goldfish, both r-mtFSH and r-mtLH were as effective as hCG for milt production in male goldfish. Recently, Kobayashi et al. (2006) reported that recombinant goldfish FSH and $\mathrm{LH}$ produced by silkworm larvae induced milt production in male goldfish with a similar magnitude. In coho salmon (Planas \& Swanson 1995) and red seabream (Kagawa et al. 1998), both FSH and LH stimulated testicular 11-KT production in vitro. Furthermore, 11-KT was slightly effective in inducing spermiation in goldfish in vivo (Ueda et al. 1985). These results suggest that both r-mtFSH and r-mtLH activate a final phase of testicular development via, at least partly, 11-KT production in male fish.
In summary, biologically active r-mtFSH and r-mtLH have been produced successfully in the baculovirussilkworm system. The r-mtFSH and r-mtLH were highly specific for their cognate receptors, although the efficacy of signal transduction by r-mtLH was stronger than that of r-mtFSH. The production of $\mathrm{E} 2$ and T were stimulated by the r-mtFSH and r-mtLH respectively, from fully grown follicles of rainbow trout in vitro, whereas both $\mathrm{E} 2$ and $\mathrm{T}$ increased by the follicles of maturing stage reacting with both $\mathrm{r}-\mathrm{mtFSH}$ and $\mathrm{r}$-mtLH. In immature rainbow trout, a single injection with $\mathrm{r}$-mtFSH increased ovarian weights and follicular diameters at 3 days post-injection. Furthermore, in the r-mtFSH-injected fish, vitellogenic oocytes were frequently observed and plasma E2 levels were higher than those of control fish. In r-mtLH-treated fish, plasma $\mathrm{T}$ levels and GSI values were not significantly different from those of control fish, although these parameters showed a tendency to increase. Both r-mtFSH and r-mtLH were highly effective for milt production in male goldfish.

\section{Acknowledgements}

We thank Dr Yoshitaka Nagahama, National Institute for Basic Biology, Okazaki, Aichi, Japan, for supplying the amago salmon GTH receptor plasmids. We also thank Mi-Ae Kim of Kangnung National University for technical support and the personnel of Salmon Research Center, East Sea Fisheries Research Institute, Yang-Yang, Gangwon-do, Korea, especially Drs Chae Sung Lee and Cheul Ho Lee for providing and maintenance of experimental fish. This work was supported by Grants-in-Aid from the JSPS, Japan, for Japan-Korea Basic Scientific Cooperation (M K), and grants from KOSEF for Joint Research Project under Korea-Japan Basic Scientific Cooperation Program and from the Ministry of Maritime Affairs and Fisheries, Korea, for KSGP and MarineBio21 program (Y C S). H Ko and W Park are recipients of a graduate fellowship provided by the Brain Korea (BK21) program sponsored by the Ministry of Education and Human Resources Development, Korea. The authors declare that there is no conflict of interest that would prejudice the impartiality of this scientific work.

\section{References}

Aida K, Kato T \& Awaji M 1984 Effects of castration on the smoltification of precocious male masu salmon, Oncorhynchus masou. Nippon Suisan Gakkaishi 50 565-571.

Arukwe A, Kullman SW \& Hinton DE 2001 Differential biomarker gene and protein expressions in nonylphenol and estradiol-17 $\beta$ treated juvenile rainbow trout (Oncorhynchus mykiss). Comparative Biochemistry and Physiology Part C 129 1-10. 
Bogerd J, Blomenrohr M, Andersson E, van der Putten HH, Tensen CP, Vischer HF, Granneman JC, Janssen-Dommerholt C, Goos HJ \& Schulz RW 2001 Discrepancy between molecular structure and ligand selectivity of a testicular follicle-stimulating hormone receptor of the African catfish (Clarias gariepinus). Biology of Reproduction 64 1633-1643.

Bogerd J, Granneman JC, Schulz RW \& Vischer HF 2005 Fish FSH receptors bind LH: how to make the human FSH receptor to be more fishy? General and Comparative Endocrinology 142 34-43.

Choi E, Ko H, Shin J, Kim M \& Sohn YC 2005 Expression of gonadotropin genes in Manchurian trout Brachymystax lenok and production of recombinant gonadotropins. Fisheries Science 71 1193-1200.

Dufau ML 1998 The luteinizing hormone receptor. Annual Review of Physiology 60 461-496.

Gen K, Okuzawa K, Kumakura N, Yamaguchi S \& Kagawa H 2001 Correlation between messenger RNA expression of cytochrome P450 aromatase and its enzyme activity during oocyte development in the red seabream (Pagrus major). Biology of Reproduction 65 $1186-1194$.

Kagawa H, Young G \& Nagahama Y 1982 Estradiol-17 $\beta$ production in isolated amago salmon (Oncorhynchus rhodurus) ovarian follicles and its stimulation by gonadotropins. General and Comparative Endocrinology 47 361-365.

Kagawa H, Tanaka H, Okuzawa K \& Kobayashi M 1998 GTH II but not GTH I induces final oocyte maturation and the development of maturational competence of oocytes of red seabream in vitro. General and Comparative Endocrinology 112 80-88.

Kagawa H, Gen K, Okuzawa K \& Tanaka H 2003 Effects of luteinizing hormone and follicle-stimulating hormone and insulin-like growth factor-I on aromatase activity and P450 aromatase gene expression in the ovarian follicles of red seabream, Pagrus major. Biology of Reproduction 68 1562-1568.

Kamei H, Ohira T, Yoshiura Y, Uchida N, Nagasawa H \& Aida K 2003 Expression of a biologically active recombinant follicle stimulating hormone of Japanese eel Anguilla japonica using methylotropic yeast, Pichia pastoris. General and Comparative Endocrinology 134 244-254.

Kasuto H \& Levavi-Sivan B 2005 Production of biologically active tethered tilapia LH $\beta \alpha$ by the methylotrophic yeast Pichia pastoris. General and Comparative Endocrinology 140 222-232.

Klein J, Lobel L, Pollak S, Lustbader B, Ogden RT, Sauer MV \& Lustbader JW 2003 Development and characterization of a longacting recombinant hFSH agonist. Human Reproduction 18 50-56.

Kobayashi M, Morita T, Ikeguchi K, Yoshizaki G, Suzuki T \& Watabe S 2006 In vivo biological activity of recombinant goldfish gonadotropins produced by baculovirus in silkworm larvae. Aquaculture $\mathbf{2 5 6}$ 433-442.

Kumar RS \& Trant JM 2001 Piscine glycoprotein hormone gonadotropin and thyrotropin receptors: a review of recent developments. Comparative Biochemistry and Physiology Part B 129 347-355.

Kumar RS, Ijiri S \& Trant JM 2001 a Molecular biology of channel catfish gonadotropin receptors: 1 . Cloning of a functional luteinizing hormone receptor and preovulatory induction of gene expression. Biology of Reproduction 64 1010-1018.

Kumar RS, Ijiri S \& Trant JM $2001 b$ Molecular biology of the channel catfish gonadotropin receptors: 2. Complementary DNA cloning, functional expression, and seasonal gene expression of the folliclestimulating hormone receptor. Biology of Reproduction 65 710-717.

Kwok HF, So WK, Wang Y \& Ge W 2005 Zebrafish gonadotropins and their receptors: I. Cloning and characterization of zebrafish folliclestimulating hormone and luteinizing hormone receptors evidence for their distinct functions in follicle development. Biology of Reproduction 72 1370-1381.

Loir M 1999 Spermatogonia of rainbow trout: II. In vitro study on the influence of pituitary hormones, growth factors and steroids on mitotic activity. Molecular Reproduction and Development 53 434-442.
Maeda S 1989 Gene transfer vectors of a baculovirus, Bombyx mori, and their use for expression of foreign genes in insect cells. In Invertebrate Cell System Applications, pp 167-181. Ed J Mitsuhashi. J. Florida: CRC Press.

Miwa S, Yan L \& Swanson P 1994 Localization of two gonadotropin receptors in the salmon gonad by in vitro ligand autoradiography. Biology of Reproduction $\mathbf{5 0}$ 629-642.

Morita T, Yoshizaki G, Kobayashi M, Watabe S \& Takeuchi T 2004 Fish eggs as bioreactors: the production of bioactive luteinizing hormone in transgenic trout embryos. Transgenic Research 13 551-557.

Nagler JJ \& Idler DR 1991 Stimulation of in vitro ovarian estradiol-17 beta synthesis in the rainbow trout by the carbohydrate-poor protein fraction from sockeye salmon pituitary glands. Journal of Steroid Biochemistry and Molecular Biology 39 513-518.

Oba Y, Hirai T, Yoshiura Y, Yoshikuni M, Kawauchi H \& Nagahama Y $1999 a$ Cloning, functional characterization, and expression of a gonadotropin receptor cDNA in the ovary and testis of amago salmon Oncorhynchus rhodurus. Biochemical and Biophysical Research Communications 263 584-590.

Oba Y, Hirai T, Yoshiura Y, Yoshikuni M, Kawauchi H \& Nagahama Y $1999 b$ The duality of fish gonadotropin receptors: cloning and functional characterization of a second gonadotropin receptor cDNA expressed in the ovary and testis of amago salmon Oncorhynchus rhodurus. Biochemical and Biophysical Research Communications 265 366-371.

Okada T, Kawazoe I, Kimura S, Sasamoto Y, Aida K \& Kawauchi H 1994 Purification and characterization of gonadotropin I and II from pituitary glands of tuna (Thunnus obesus). International Journal of Peptide and Protein Research 43 69-80.

Pierce JG \& Parsons TF 1981 Glycoprotein hormones: structure and function. Annual Review of Biochemistry 50 465-495.

Planas JV \& Swanson P 1995 Maturation-associated changes in the response of the salmon testis to the steroidogenic actions of gonadotropins, GTH I and GTH II, in vitro. Biology of Reproduction 52 697-704.

Planas JV, Athos J, Goetz FW \& Swanson P 2000 Regulation of ovarian steroidogenesis in vitro by follicle-stimulating hormone and luteinizing hormone during sexual maturation in salmonid fish. Biology of Reproduction 62 1262-1269.

Shin J, Oh D \& Sohn YC 2006 Molecular characterization and expression analysis of stanniocalcin-1 in turbot (Scophthalmus maximus). General and Comparative Endocrinology 147 214-221.

Simoni M, Gromoll J \& Nieschlag E 1997 The follicle-stimulating hormone receptor: biochemistry, molecular biology, physiology, and pathophysiology. Endocrine Reviews 18 739-773.

So WK, Kwok HF \& Ge W 2005 Zebrafish gonadotropins and their receptors: II. Cloning and characterization of zebrafish folliclestimulating hormone and luteinizing hormone subunits their spatial-temporal expression patterns and receptor specificity. Biology of Reproduction 72 1382-1396.

Suzuki K, Kawauchi H \& Nagahama Y 1988 a Isolation and characterization of subunits of two distinct gonadotropins from chum salmon pituitary glands. General and Comparative Endocrinology 71 302-306.

Suzuki K, Nagahama Y \& Kawauchi H $1988 b$ Steroidogenic activities of two distinct salmon gonadotropins. General and Comparative Endocrinology 71 452-458.

Swanson P, Dickey JT \& Campbell B 2003 Biochemistry and physiology of fish gonadotropins. Fish Physiology and Biochemistry 28 53-59.

Tanaka H, Kagawa H, Okuzawa K \& Hirose K 1993 Purification of gonadotropins (pmGTH I and II) from red seabream (Pagrus major) and development of homologous radioimmunoassay for pmGTH II. Fish Physiology and Biochemistry 10 409-418.

Tyler CR, Sumpter JP, Kawauchi H \& Swanson P 1991 Involvement of gonadotropin in the uptake of vitellogenin into vitellogenic oocytes of the rainbow trout, Oncorhynchus mykiss. General and Comparative Endocrinology 84 291-299. 
Tyler CR, Pottinger TC, Coward K, Prat F, Beresford N \& Maddix S 1997 Salmonid follicle-stimulating hormone (GtH I) mediates vitellogenic development of oocytes in the rainbow trout. Oncorhynchus mykiss. Biology of Reproduction 57 1238-1244.

Ueda H, Kambegawa A \& Nagahama Y 1985 Involvement of gonadotrophin and steroid hormones in spermiation in the amago salmon, Oncorhynchus rhodurus, and goldfish, Carassius auratus. General and Comparative Endocrinology 59 24-30.

Ulloa-Aguirre A, Timossi C, Damian-Matsumura P \& Dias JA 1999 Role of glycosylation in function of follicle-stimulating hormone. Endocrine 11 205-215.

Van Der Kraak G, Suzuki K, Peter RE, Itoh H \& Kawauchi H 1992 Properties of carp gonadotropin I and gonadotropin II. General and Comparative Endocrinology 85 217-229.

Vischer HF \& Bogerd J 2003 Cloning and functional characterization of a gonadal luteinizing hormone receptor complementary DNA from the African catfish (Clarias gariepinus). Biology of Reproduction 68 262-271.

Vischer HF, Granneman JC, Linskens MH, Schulz RW \& Bogerd J 2003 Both recombinant African catfish LH and FSH are able to activate the African catfish FSH receptor. Journal of Molecular Endocrinology 31 133-140.
Yan L, Swanson P \& Dickhoff WW 1992 A two-receptor model for salmon gonadotropins (GTH I and GTH II). Biology of Reproduction 47 418-427.

Yaron Z, Gur G, Melamed P, Rosenfeld H, Elizur A \& Levavi-Sivan B 2003 Regulation of fish gonadotropins. International Review of Cytology 225 131-185.

Zenkevics H, Vose V, Vosekalne I \& Bucena A 2000 Partial deglycosylation of alpha subunit modifies sturgeon gonadotropin function. Acta Biochimica Polonica 47 815-819.

Zmora N, Kumar S, Kazeto Y \& Trant JM 2003 Production of channel catfish (Ictalurus punctatus) recombinant gonadotropins using the S2 Drosophila cell line system. Fish Physiology and Biochemistry 28 $475-477$.

Received 9 October 2006

Accepted 8 November 2006

Made available online as an Accepted Preprint on 17 November 2006 